\title{
Editorial: Friction and Wear: From Elementary Mechanisms to Macroscopic Behavior
}

\author{
Roman Pohrt* and Valentin L. Popov* \\ Department of System Dynamics and Friction Physics, Technische Universität Berlin, Berlin, Germany
}

Keywords: friction, wear, adhesion, viscoelasticity, superlubricity, contact area, atomistic simulations, scales

\section{Editorial on the Research Topic}

\section{Friction and Wear: From Elementary Mechanisms to Macroscopic Behavior}

In the last 25 years, the global trend toward miniaturization has raised interest in frictional processes on the micro and nanoscale, and has facilitated the appearance of nanotribology as a new branch of research. Soon it became clear that looking at tribological processes at micro- and nanoscale can be very fruitful for macroscopic systems. Researchers recognized that these processes determine the macroscopic behavior via a number of mesoscopic levels. At first, this was perceived as a "gap" between macro and micro worlds. Over time, countless attempts were undertaken to "fill the gap"-both top-down and bottom-up.

The top-down approach starts from continuous macroscopic contact mechanics. A breakthrough in the modeling of real surfaces was connected with the development of the Fast Fourier-based Boundary Element Method (Campañá and Müser, 2006; Pohrt and Li, 2014). It allowed the analyzing of surfaces with ever-increasing levels of roughness discretization, and lead to "revisiting" and a new understanding of many old tribological solutions (e.g., Yastrebov et al.,

OPEN ACCESS

Edited and reviewed by: Emile Van Der Heide, Faculty of Engineering Technology, University of Twente, Netherlands

*Correspondence: Roman Pohrt roman.pohrt@tu-berlin.de Valentin L. Popov v.popov@tu-berlin.de

Specialty section: This article was submitted to Tribology,

a section of the journal Frontiers in Mechanical Engineering

Received: 19 June 2019

Accepted: 18 July 2019

Published: 02 August 2019

Citation:

Pohrt R and Popov VL (2019) Editorial: Friction and Wear: From Elementary Mechanisms to Macroscopic Behavior. Front. Mech. Eng. 5:47. doi: 10.3389/fmech.2019.00047 2015). The present state in this field of contact mechanics of real surfaces is documented in a much-debated paper (Müser et al., 2017) written by 35 authors, as well as in the recent review (Vakis et al., 2018) written by 27 experts in the field. The bottom-up approach is connected with the development of measurement techniques at nano-level (Robbins and Krim, 1998; Gnecco and Meyer, 2015), as well as simulation techniques at the atomic and molecular level (Robbins and Müser, 2001; Pastewka et al., 2010). This approach brought into play fundamental concepts such as structural superlubricity (Erdemir and Martin, 2007) and thin fluid layer behavior, which were essential for understanding boundary lubrication (Erdemir, 2005).

The present Article Collection is an illustration of the current state of attempts to bring micro and macro together. It is opened by a review "Controlling Friction With External Electric or Magnetic Fields: 25 Examples" by Krim. Both the title and the author are symbolic for the topic. In the late 1990s, her experimental works on interfacial energy dissipation made an important contribution to the emerging field of nanotribology, and generally the physical understanding of interfacial processes. The review presents 25 examples of active control of friction from recent literature, thus reminding us of the huge complexity of tribological phenomena. At the same time, it clearly shows that they can be understood and well-controlled.

One of the most fundamental concepts discovered and analyzed in the last 25 years is the concept of superlubricity. It is classified in solid (or structural) superlubricity and liquid superlubricity, both of which are addressed in this article collection. In their paper "Macroscale Superlubricity Achieved With Various Liquid Molecules: A Review," Ge et al. discuss the advancements in liquid superlubricity at the macroscale.

Müser combines the fundamental understanding of structural superlubricity with the advances of the contact mechanics of rough surfaces. He successfully links the scales and answers the question "Are There Limits to Superlubricity of Graphene in Hard, Rough Contacts?" 
Any mechanism of friction considered at the atomic scale can be seen as the formation and destruction of intermolecular bonds, or small scale "adhesive contacts." Therefore, it is not surprising that the adhesive interaction of rough surfaces has long been of interest to friction physicists (Fuller and Tabor, 1975). Li et al. employ a recent numerical technique to analyze both spreading and detaching of rough surfaces. Their paper, "Adhesive Strength of Contacts of Rough Spheres," gives important implications: It is found that the short range adhesion is dependent only on one single parameter introduced by Johnson (1995)!

Surface roughness is the key factor leading to a scaledependency of the "real contact area." One of the central problems and challenges here is to not only determine the surface profile at one moment in time, but to also follow its development during the relative sliding of bodies (Popov, 2018). The paper "Evolution of the True Contact Area of Laser Textured Tungsten Under Dry Sliding Conditions" by Lechthaler et al. is devoted to an experimental investigation of the true contact area. In their work, a combination of methods was used to estimate the development of the real contact surface, and the results were compared with the evolution of the coefficient of friction.

Kovalev et al. present an efficient way of predicting wear evolution. They devote their paper "A concept of the effective surface profile to predict the roughness parameters of worn surface" to a theoretical study of the development of surface topography.

The paper "Atomistic Insights Into Lubricated Tungsten/Diamond Sliding Contacts" by Romero et al. is an excellent illustration of the possibilities of both contemporary atomistic modeling and experimental analysis at the atomic scale. The authors reveal the chemical roots of the very low friction resistance in that system. It is the formation of a

\section{REFERENCES}

Campañá, C., and Müser, M. H. (2006). Practical Green's function approach to the simulation of elastic semi-infinite solids. Phys. Rev. B 74:7. doi: 10.1103/physrevb.74.075420

Erdemir, A. (2005). Review of engineered tribological interfaces for improved boundary lubrication. Tribol. Int. 38, 249-256. doi: 10.1016/j.triboint.2004.08.008

Erdemir, A., and Martin, J.-M. (eds.). (2007). Superlubricity. Elsevier. doi: 10.1016/B978-0-444-52772-1.X5029-X

Fuller, K. N. G., and Tabor, D. (1975). The effect of surface roughness on the adhesion of elastic solids. Proc. R. Soc. A Math. Phys. Eng. Sci. 345, 327-342. doi: $10.1098 /$ rspa.1975.0138

Gnecco, E., and Meyer, E. (eds.). (2015). Fundamentals of Friction and Wear on the Nanoscale. NanoScience and Technology. doi: 10.1007/978-3-319-10560-4

Johnson, K. L. (1995). The adhesion of two elastic bodies with slightly wavy surfaces. Int. J. Solids Struct. 32, 423-430. doi: 10.1016/0020-7683(94)00111-9

Müser, M. H., Dapp, W. B., Bugnicourt, R., Sainsot, P., Lesaffre, N., Lubrecht, T. A., et al. (2017). Meeting the contact-mechanics challenge. Tribol. Lett. 65:4. doi: 10.1007/s11249-017-0900-2

Pastewka, L., Moser, S., Gumbsch, P., and Moseler, M. (2010). Anisotropic mechanical amorphization drives wear in diamond. Nat. Mater. 10, 34-38. doi: $10.1038 /$ nmat2902

Pohrt, R., and Li, Q. (2014). Complete boundary element formulation for normal and tangential contact problems. Phys. Mesomech. 17, 334-340. doi: $10.1134 /$ s1029959914040109 hydrocarbon film, preventing the partners from cold welding!

An intermediate scale between atomic and macroscopic is the scale of single asperities. Atomic force microscopy is the method of choice for experimental research at this scale. The authors of the paper "Role of Interfacial Water and Applied Potential on Friction at $\mathrm{Au}(111)$ surfaces" investigate how, in the presence of interfacial water, friction can be controlled by an electric field (Pashazanusi et al.).

Friction in soft matter, including elastomers, can be directly linked to rheological properties, but such understanding is not extensive. The experimental study in the paper "Investigation on Dynamic Response of Rubber in Frictional Contact" shows that we are still far from understanding how the dynamic response in frictional contacts should be described (Nakano et al.).

A practical example in the form of a seal in machining tools is given in the last paper by researchers from Kumamoto University (Akiyama et al.).

Tribologists will continue their quest to "bridge the gap" between nano and macro scale and the current article collection is a representative landmark in this endeavor. We hope you will find it inspiring.

\section{AUTHOR CONTRIBUTIONS}

All authors listed have made a substantial, direct and intellectual contribution to the work, and approved it for publication.

\section{ACKNOWLEDGMENTS}

The authors acknowledge financial support of the German Research Society (DFG), Project numbers PO 810/55-1, PO 810/53-1, PO 810/48-1.

Popov, V. L. (2018). Is tribology approaching its golden age? Grand challenges in engineering education and tribological research. Front. Mech. Eng. 4:16. doi: 10.3389/fmech.2018.00016

Robbins, M. O., and Krim, J. (1998). Energy dissipation in interfacial friction. MRS Bull. 23, 23-26. doi: 10.1557/s088376940003058x

Robbins, M. O., and Müser, M. H. (2001). "Computer simulations of friction, lubrication and wear," in Handbook of Modern Tribology Chapter 20, ed B. Bhushan (Bosa Roca: CRC Press).

Vakis, A. I., Yastrebov, V. A., Scheibert, J., Nicola, L., Dini, D., Minfray, C., et al. (2018). Modeling and simulation in tribology across scales: an overview. Tribol. Int. 125, 169-199. doi: 10.1016/j.triboint.2018.02.005

Yastrebov, V. A., Anciaux, G., and Molinari, J.-F. (2015). From infinitesimal to full contact between rough surfaces: evolution of the contact area. Int. J. Solids Struct. 52, 83-102. doi: 10.1016/j.ijsolstr.2014. 09.019

Conflict of Interest Statement: The authors declare that the research was conducted in the absence of any commercial or financial relationships that could be construed as a potential conflict of interest.

Copyright (c) 2019 Pohrt and Popov. This is an open-access article distributed under the terms of the Creative Commons Attribution License (CC BY). The use, distribution or reproduction in other forums is permitted, provided the original author(s) and the copyright owner(s) are credited and that the original publication in this journal is cited, in accordance with accepted academic practice. No use, distribution or reproduction is permitted which does not comply with these terms. 